\title{
Pattern of Chemical Ocular Injury: A Clinical Study
}

\author{
Subrata Das ${ }^{1 *}$ \\ Md. Firoz Kabir ${ }^{1}$ \\ Joyabrata Das ${ }^{2}$ \\ Ahmed Abdul Hannan \\ Md. Wazed Chowdhury \\ Saiem Mohd Nurul Anwar ${ }^{2}$ \\ Rajiv Mothey ${ }^{\top}$ \\ 'Department of Ophthalmology \\ Chittagong Medical College \\ Chittagong, Bangladesh. \\ ${ }^{2}$ Department of Medicine \\ Southern Medical College \\ Chittagong, Bangladesh.
}

\begin{abstract}
Background: Chemical ocular injury is a common injury among the population of Bangladesh. This present study in aimed to evaluate the pattern of chemical ocular injury in our context. Methods: This cross-sectional observational study was done among 50 patients of chemical ocular injury by different substances between January and June 2013. After initial evaluation patients were also followed up for next 3 months to evaluate the visual outcome. Results: Male to female ratio was 1.7:1. Males between 21-30 years and 41-50 years were mostly affected whereas females of 41-50 were affected most. Most commonly affected occupation was service (36\%) followed by housewives $(22 \%)$ and majority $(58 \%)$ were from low socio-economic conditions. Thirty five (70\%) cases were alkali burn and remainder $15(30 \%)$ were acid burn. Among alkali, hydrated lime $\mathrm{Ca}(\mathrm{OH})_{2}$ had highest percentage $82.8 \%$. Most (46\%) patients with good visual acuity i.e. $6 / 12-6 / 24$ belongs to early (less than six hours) reporting time interval. It was found that $48 \%$ were grade - I and 34\% cases were grade - II injury and other grades were not pronounced. Study showed that improvement of visual acuity after initial management and subsequent treatment was significant. Conclusion: Alkali burn is the common pattern of ocular injury in our country where lime is the common chemical substance. Early intervention is essential to avoid long term visual disability.
\end{abstract}

Key words: Chemical ocular injury; alkali; acid; visual acuity.

\section{INTRODUCTION}

Chemical injuries to the eyes are common and represent one of the true ophthalmic emergencies. Practically any chemical can cause ocular irritation. Most of these injuries are inconsequential and do not cause serious lesions (e.g. shampoos, defense sprays, household cleaning solutions etc.) while other may result in permanent morbidity. Severe ocular damage is most commonly associated with strong alkaline or acidic compounds ${ }^{1}$. Chemical burns may be induced by means of vapor, solid or liquid. Nonetheless the majority occur in industrial environment, in laboratories, in combative environments or as a result of an accident ${ }^{2}$. Chemical injures are potentially devastating ocular surface injures that can result in permanent visual impairment. They may cause extensive damage to the eyelids, conjunctiva, cornea and anterior segment resulting in severe morbidity including permanent unilateral or bilateral blindness. As with other injuries the nature of the chemical burning is variable and dependent on local circumstances. It is important to note the type of chemical, because the mechanism of injury varies between acidic and alkaline exposure ${ }^{3-4}$. Common acids are sulfuric acid (car batteries), hydrofluoric acid (glass polishing), acetic acid, hydrochloric acid and nitric acid(gold maker). Common alkalis are lime(plaster),ammonia/ammonium hydrochloride (cleaning solution, drain cleaner), potassium hydrochloride, magnesium hydrochloride (fireworks). Acid burns is usually less severe than that caused by alkali burn. When acid comes contact with corneal surface they cause coagulation of tissue protein forming a barrier, which prevents deep penetration ${ }^{5}$.

\section{Dr. Subrata Das}

Department of Ophthalmology

Chittagong Medical College

Chittagong, Bangladesh.

Mobile: +8801819643928

E-mail:drdasib@gmail.com 
But alkalis in contrast, cause saponification of cellular lipids disrupt the normal barrier of the cornea resulting in deep penetration to internal structures causing severe damage to the lens and anterior uvea. In severe cases phthisis bulbi may be the tragic end result ${ }^{6}$. The severity of a chemical injury is related to the concentration of the chemical, properties of the chemical, the duration of contact with the ocular tissue, the area of the effected surface, retention of the particulate chemical on the surface of the globe, the chemical reaction with the tissue component and the diffusibility of the agent ${ }^{7}$. Chemical injury is the one of the true ophthalmic emergency and it needs immediate management. Chemical burns have a major impacts in terms of long term morbidity and so is a matter of major socio-economic importance ${ }^{8-9}$. The squeals of chemical burn may have significant detrimental visual and psychological effects on the affected individual. Chemical injury to the eye accounts for a significant portion of ocular trauma. Proper management in the acute setting as well as follow-up by an ophthalmologist is crucial in limiting adverse effects of ocular tissue damage secondary to the chemicals. So this cross sectional study is aimed to describe the common pattern of chemical ocular injury and its type and short term outcome so that it can be used in future for planning to prevent chemical ocular injury in our context.

The aim of this study was to find out the pattern of ocular injury, nature of causative chemicals, the disabilities incurred and the outcome of treatment.

\section{MATERIALS \& METHODS}

This descriptive cross-sectional study was carried out in the Department of Ophthalmology of Chittagong Medical College Hospital (CMCH), Chittagong, Bangladesh between January 1, 2013 and June 30, 2013. All 50 patients of documented ocular chemical injury admitted in Department of Ophthalmology, $\mathrm{CMCH}$ were included.

Inclusion Criteria:

1. Patients with chemical injury to the eyes.

2. Age $12-60$ years.

3. Voluntarily given consent to participate in the study.

Exclusion criteria

1. Associated injury to other parts of the body.

2. Preexisting ocular pathology.

3. Senility (Age $>60$ years).

Chemical Injury to eye was defined as any insult to one or both eye external or internal with chemical substances, irritant powder or gas. Acidity or alkalinity was confirmed by litmus paper test.

From all eligible subjects after getting consent clinical history was taken and clinical examination was done to elicit findings related to eye injury and its complication. Related ocular examination like slit lamp examination, visual acuity test and ophthalmoscopy was also done. Conjunctival swab was taken to find out any eye infection. All relevant data were included in the data sheet. All data were collected by researcher himself. All data were recorded systematically in preformed data collection form and quantitative data were expressed as mean and standard deviation and qualitative data were expressed as frequency distribution and percentage.
Statistical analysis was performed by using SPSS (Statistical Package for Social Sciences) for windows version 19.0. 95\% confidence limit was taken. Probability value $<0.05$ was considered as level of significance. Prior to the commencement of this study, the protocol was approved by the ethical committee of Chittagong Medical College Hospital, Chittagong.

\section{RESULTS}

Male to female ratio was 1.7:1. Males between 21-30 years and 41-50 years were mostly affected whereas females of 41-50 were affected most (Table 1). Affected males were predominantly service holders whereas females were housewives (Table 2). Majority (58\%) were from low socioeconomic conditions. Thirty five $(70 \%)$ cases were alkali burn and remainder was acid burn. Among alkali, hydrated lime $\mathrm{Ca}$ $(\mathrm{OH})_{2}$ had highest percentage $82.8 \%$ (Table 3 ). Large number of patients $(46 \%)$ with good visual acuity i.e. 6/12 - 6/24 belongs to early (less than six hours) reporting group (Table 4). It was found that $48 \%$ were grade - I and $34 \%$ cases were grade - II injury and other grades were not pronounced (Table 5). Stromal edema was the leading complication (Table 6). Improvement of visual acuity after initial management and subsequent treatment was significant (Table $7 \& 8$; figures $1 \& 2$ ).

Table 1: Prevalence of eye lesion by age and sex $(n=50)$ :

\begin{tabular}{ccc} 
Age (years) & Male & Female \\
$12-20$ & $3(6 \%)$ & $3(6 \%)$ \\
$21-30$ & $12(24 \%)$ & $2(4 \%)$ \\
$31-40$ & $4(8 \%)$ & $3(6 \%)$ \\
$41-50$ & $10(20 \%)$ & $7(14 \%)$ \\
$51-60$ & $3(6 \%)$ & $3(6 \%)$ \\
Total & 32 & 18 \\
\hline
\end{tabular}

Table 2: Occupation of the patient $(\mathrm{n}=50)$ :

\begin{tabular}{lccc} 
Occupation & Male & Female & Total \\
Student & 1 & 4 & 5 \\
Housewife & 0 & 11 & 11 \\
Service & 17 & 1 & 18 \\
Business & 8 & 0 & 8 \\
Others & 6 & 2 & 8 \\
\hline
\end{tabular}

Table 3: Showing prevalence of different types of alkali and acid $(n=50)$ :

Type of chemical No. of patient / Percentage

$\begin{array}{cclc}\text { Acids } & \text { Sulfuric acid } & 6(40 \%) & (\mathrm{p}>0.05) \\ & \text { Nitric acid } & 5(33.33 \%) & (\mathrm{p}>0.05) \\ & \text { Others } & 4(26.77 \%) & (\mathrm{p}>0.05) \\ \text { Alkali } & \text { Lime } & 29(82.8 \%) & (\mathrm{p}>0.05) \\ & \text { Ammonia } & 6(17.2 \%) & (\mathrm{p}>0.05)\end{array}$


Table 4: Shows visual outcome in relation with reporting time interval $(\mathrm{n}=50)$ :

$\begin{array}{lccccccccc}\begin{array}{l}\text { Reporting } \\ \text { time } \\ \text { interval }\end{array} & \text { better } & 6 / 24 & 6 / 12-6 / 36- & \text { CF }(5-10) & \text { CF }(1-4) & \text { HM } & \text { PL } & \text { NPL } \\ \text { Feet } & & & & & & & & \\ 6 \text { hours } & 8 & 23 & 0 & 1 & 0 & 1 & 0 & 0 \\ 12 \text { hours } & 4 & 7 & 1 & 1 & 0 & 0 & 0 & 0 \\ 24 \text { hours } & 0 & 0 & 1 & 1 & 0 & 1 & 0 & 1\end{array}$

Table 5: Severity of injury $(n=50)$

\begin{tabular}{lcccc} 
Grading & Male & Female & \multicolumn{2}{c}{ Total } \\
Grade - I & 15 & 9 & $24(48 \%)$ & $(\mathrm{p}>0.05)$ \\
Grade - II & 11 & 6 & $17(34 \%)$ & $(\mathrm{p}>0.05)$ \\
Grade - III & 4 & 2 & $6(12 \%)$ & $(\mathrm{p}>0.05)$ \\
Grade - IV & 2 & 1 & $3(6 \%)$ & $(\mathrm{p}>0.05)$ \\
\hline
\end{tabular}

Table 6: Complications following chemical burn $(n=50)$ :

\begin{tabular}{lcc} 
Complications & Male & Female \\
Stromal edema & $23(56 \%)$ & $14(28 \%)$ \\
Sterile corneal ulcer & $2(4 \%)$ & $0(00 \%)$ \\
Corneal perforation & 0 & 0 \\
$\begin{array}{l}\text { Corneal opacity with or } \\
\text { without vascularization }\end{array}$ & $5(10 \%)$ & $3(6 \%)$ \\
Symblepheron & $4(8 \%)$ & $2(4 \%)$ \\
Cataract formation & $3(6 \%)$ & $1(2 \%)$ \\
Ectropion & $1(2 \%)$ & 0 \\
Entropion & $2(4 \%)$ & $1(2 \%)$ \\
Phthisis bulbi & $1(2 \%)$ & 0 \\
\hline p $>0.05:$ Stromal edema & &
\end{tabular}

Table 7: Showing follow up monitoring of visual acuity between one to three months after initial injury $(\mathrm{n}=50)$ :

$\begin{array}{lccccc}\text { Visual acuity } & \begin{array}{c}\text { After } \\ \text { admission }\end{array} & \begin{array}{c}\text { During } \\ \text { discharge }\end{array} & \begin{array}{c}\text { After } \\ 1 \text { month }\end{array} & \begin{array}{c}\text { After } \\ 2 \text { months }\end{array} & \begin{array}{c}\text { After } \\ 3 \text { months }\end{array} \\ \text { 6/9 or better } & 0 & 6 & 8 & 10 & 10 \\ 6 / 12-6 / 24 & 12 & 20 & 22 & 24 & 27 \\ 6 / 36-6 / 60 & 23 & 15 & 12 & 10 & 5 \\ \text { CF(5-10 ft) } & 6 & 5 & 4 & 3 & 4 \\ \text { CF(1-4 ft) } & 4 & 1 & 1 & 0 & 0 \\ \text { HM } & 3 & 2 & 1 & 1 & 2 \\ \text { PL } & 1 & 0 & 0 & 0 & 0 \\ \text { NPL } & 1 & 1 & 1 & 1 & 1\end{array}$

Table 8: Showing visual outcome after chemical injuries $(n=50)$

\begin{tabular}{ccccc} 
Visual acuity & Male & Female & \multicolumn{2}{c}{ Total } \\
6/9 or better & $5(10 \%)$ & $5(10 \%)$ & 10 & $(\mathrm{p}>0.05)$ \\
$6 / 12-6 / 24$ & $20(40 \%)$ & $8(16 \%)$ & 28 & $(\mathrm{p}>0.05)$ \\
$6 / 36-6 / 60$ & $3(6 \%)$ & $2(4 \%)$ & 5 & \\
$\mathrm{CF}(5-10 \mathrm{ft})$ & $2(4 \%)$ & $2(4 \%)$ & 4 & $(\mathrm{p}<0.05)$ \\
$\mathrm{CF}(1-4 \mathrm{ft})$ & 0 & 0 & & \\
HM & $1(2 \%)$ & $1(2 \%)$ & 2 & $(\mathrm{p}<0.05)$ \\
PL & 0 & 0 & & \\
NPL & $1(2 \%)$ & 0 & 1 &
\end{tabular}

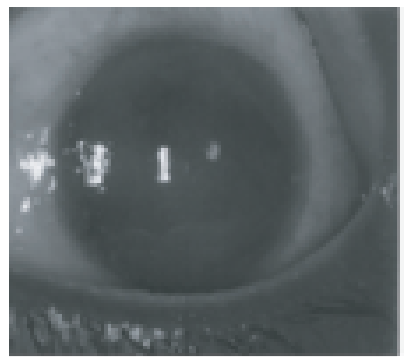

Tgure Ia: Case 1- Alkali burn efore treatment

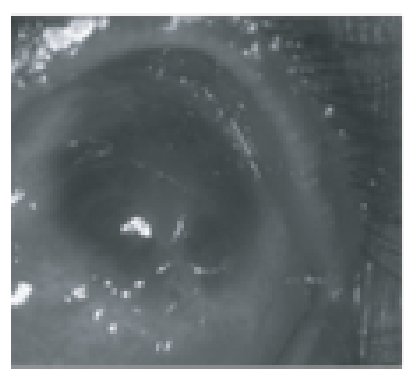

igure 2a: Case 2-Alkali um before treatment

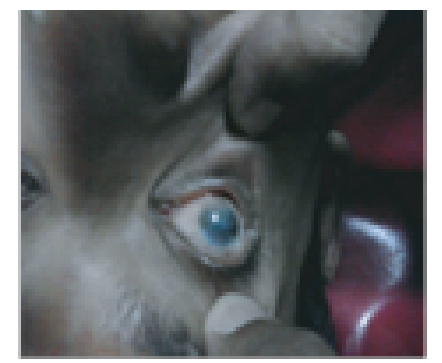

Figure Ib: Case 1-After treatment

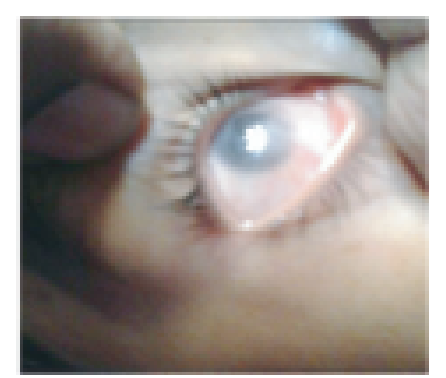

Figure 2b: Case 2-After treatment

\section{DISCUSSION}

The distribution of the injuries on various ages has shown considerable variations. Majority of the patient with ocular affection was young adult. It was about two third of total patients; which is almost similar findings of Saini-Sharma ${ }^{8}$. They stated that young people works in laboratories and factories constitute two-thirds of the patients of chemical injury. This assumption perhaps true on our study as well, more over in Bangladesh this age group sometimes become victim for assault leading to higher prevalence. As the age advanced the incidence of chemical injuries is gradually decreased. Among the victim majority of the patients (36\%) were service man. Their nature of the job was different, like industrial worker, building construction worker, fertilizer industry etc. They were accidentally injured by the chemical substance at their work place. Also accidental injury to housewives and children by hydrated lime was common. Here we classified them in different income group in the basis of per day income and presence of land and other properties. 
Low income group has no land and their daily income is 100 taka or less. Middle income group has land properties, in case of village and in urban they can earn 100-200 taka per day. We considered high income group those can afford standard life style. Here we have got higher percentage $58 \%$ of victim from low income group. This is perhaps due to their illiteracy and unconscious handling of chemical agents as well as insufficient safety measurement at their work place. In the study unilateral eye involvement is $56 \%$ and bilateral involvement was $44 \%$ Saini-Sharma shows $42.1 \%$ of bilateral injury ${ }^{8}$. Severity of injury depends upon several factors like nature of the chemical, amount of chemical substance, duration of contact with tissue, pattern of management i.e. early or late. In this study the percentage of minor injuries is $82 \%$ that is nearer to Monestame's study ${ }^{5}$. Different chemical substances are frequently responsible for injuries. These may be alkali, cleaners, acid, organic solvents, ammonia, personal hygiene products, contacts lens solution, disinfection etc. In this study chemical substance has been basically classified into acid and alkali group.

Here incidence of alkali burn is $70 \%$ and acid burn $30 \%$. Among the alkali burn $82.8 \%$ was caused by both hydrate and dry lime, remaining $17.2 \%$ caused by ammonia solution when cylinder of the fertilizer industry was burst out. In case of acid burn, the incidence of sulfuric acid burn was $40 \%$ and nitric acid burn was $33.3 \%$. So people are commonly injured by alkali than as it is widely used at home and industries. These findings are consistent with the previous study ${ }^{8}$. Chemical burns are among the most alarming of ocular emergencies. This study shows different complications caused by chemical injuries. Alkali burns result in more severe complications than acid burns, because of their capability of rapid penetration into deeper structure.
So, surface epithelium of lid, cornea and conjunctiva are rapidly damaged. As a result corneal edema, corneal ulcer developed with necrosis of conjunctival epithelium and formation of symblepheron. In the present study corneal stromal edema $(84 \%)$ is more common than symblepheron $(12 \%)$ formation. Here percentage of cataract formation (8\%) is also less as because most of the cases were of grade - I injury. Visual outcome after chemical injuries depends upon the severity of the injuries. As the injury is more severe, visual acuity will be poor. Most of the injuries were minor so that visual acuity $6 / 12-6 / 24$ were $(56 \%)$ and visual acuity $6 / 9$ or better was about $(20 \%)$. In small amount of patients visual acuity was decreased severely as because of phthisis bulbi, corneal vascularization with opacity etc. Above findings are consistent with a previous study done in Dhaka, Bangladesh ${ }^{10}$. Reporting time interval to hospital is another determinant for good visual outcome. The more the time interval the worse is the prognosis. In this study we categorized reporting time interval arbitrarily. Those reported early (less then 6 hours) to the hospital attained good visual acuity (6/12-6/24). Those nearer to the hospital irrespective to socioeconomic condition reported earlier than that came from outreach area.

\section{CONCLUSION}

Alkali is the most common agent for chemical ocular injuries. Institution of early management can save the victim from more serious complication with restoration of good visual acuity.

\section{DISCLOSURE}

All the authors declared no competing interest.

\section{REFERENCES}

1. Wagoner MD. Chemical injuries of the eye: current concepts in pathophysiology and therapy. Surv Ophthalmol. 1997;41(4):275-313.

2. Morgan SJ. Chemical burns of the eye: causes and management. Brit. J. Ophthalmol. 1987;71:854-857.

3. Wasserman R, Ginsburg C. Caustic substance injuries. J Pediater 1985;107:169-174.

4. Kanski. J. J. Clinical Ophthalmology, A systemic approach. $6^{\text {th }}$ edition; 864-868.

5. Monestam, Bjornstig. Eye injuries in Northern Sweden, Department of Ophthalmology, University of Umea, Sweden. 1991;69(1):1-5.

6. Berry J. Ocular injuries from household chemicals, University of Bristol. Division of Ophthalmology, Bristol eye hospital, Bristol, UK. 2001;14(1):5-13.

7. Albert \& Jakobiec. Principles and practice of ophthalmology, $2^{\text {nd }}$ edition, W.B. Sunders company. Vol-2:943-952.

8. Saini, Sharma. Ocular chemical burns- clinical and demographic profile. Department of Ophthalmology, Postgraduate Institute of Medical Education and Research, Chandigarh, India. 1993;19(1):67-9.

9. Karlos TA, Klein BEK. The incidence of acute hospital treated eye injuries . Arch Opthalmol. 1986;104:1473.

10. Sajed Abdul Khaleque and AKMA Muqtadir. Comparative analysis of ocular acid and alkali burn and their visual outcome. DMCH. 2000; 1(7):18-21. 